\title{
Short- and long-term cause of death in patients undergoing isolated coronary artery bypass grafting: A nationwide cohort study
}

Jawad H. Butt, MB, ${ }^{\mathrm{a}}$ Rikke Sørensen, MD, PhD, ${ }^{\mathrm{a}}$ Caroline Bäck, MD, ${ }^{\mathrm{b}}$ Peter Skov Olsen, MD, DMSc, ${ }^{\mathrm{b}}$

Kristinn Thorsteinsson, MD, PhD, ${ }^{\mathrm{c}}$ Christian Torp-Pedersen, MD, DMSc, ${ }^{\mathrm{d}}$

Gunnar H. Gislason, MD, PhD, ${ }^{e, f, g}$ Lars Køber, MD, DMSc, ${ }^{a}$ and Emil L. Fosbøl, MD, PhD ${ }^{a}$

\section{ABSTRACT}

Objectives: Knowledge of the association between time and causes of death after coronary artery bypass grafting is sparse. We examined short- and long-term mortality and cause of death in patients undergoing coronary artery bypass grafting.

Methods: With the use of Danish nationwide registries, we identified all patients undergoing isolated coronary artery bypass grafting from 1998 to 2014. Cause of death was classified as cardiovascular or noncardiovascular according to death certificates. Landmark analyses of the cumulative incidences of cardiovascular and noncardiovascular mortality after 1, 3, and 5 years after coronary artery bypass grafting were performed. Multivariable cause-specific Cox regression models were used to evaluate changes over time in the risk of all-cause, cardiovascular, and noncardiovascular mortality after 1 and 7 years after coronary artery bypass grafting, respectively.

Results: Among 37,495 included patients, 12,230 (32.6\%) died during a median follow-up of 7.4 years. Causes of death were classified as cardiovascular in 6459 patients $(52.8 \%)$ and noncardiovascular in 5771 patients $(47.2 \%)$. Within the first year, the incidence of cardiovascular death was higher compared with noncardiovascular death $(3.9 \%$ vs $1.1 \%, P<.001)$. The cumulative incidences of cardiovascular and noncardiovascular were deaths similar in the periods 1 to 3 years ( $2.3 \%$ vs $2.6 \%, P=.004), 3$ to 5 years $(3.1 \%$ vs $3.2 \%, P=.75)$, and 5 to 7 years postsurgery $(3.7 \%$ vs $4.0 \%, P=.07)$. The crude rates and adjusted risks of shortand long-term all-cause and cardiovascular mortality decreased during the study period despite an increase in age and burden of comorbidities.

Conclusions: In patients undergoing coronary artery bypass grafting, cardiovascular causes were responsible for the majority of deaths within the first year. Deaths due to noncardiovascular causes gained importance over time elapsed since coronary artery bypass grafting. (J Thorac Cardiovasc Surg 2018;156:54-60)

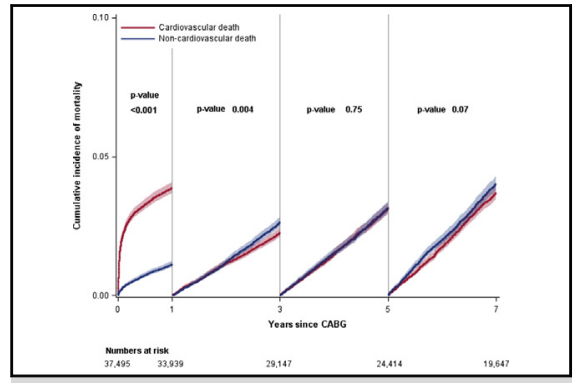

Landmark analyses of the cumulative incidences (with confidence intervals) for cardiovascular and noncardiovascular mortality at different time points in patients undergoing $\mathrm{CABG}$.

\section{Central Message}

Cardiovascular causes were responsible for the majority of deaths within the first year after CABG. Deaths due to noncardiovascular causes gained importance over time elapsed since CABG.

\section{Perspective}

Patients who survived the first year after CABG appeared increasingly likely to die from other causes than cardiovascular, reflecting that the risk of competing diseases increases with age, especially in an aging population. This knowledge will add further to the information provided to the patients at discharge after $\mathrm{CABG}$ about long-term prospects and life expectancy.

See Editorial Commentary page 61.
From the Departments of ${ }^{\mathrm{a} C a r d i o l o g y}$ and ${ }^{\mathrm{b}}$ Cardiothoracic Surgery, Rigshospitalet, Copenhagen University Hospital, Copenhagen, Denmark; Departments of ${ }^{\mathrm{c}}$ Cardiothoracic Surgery and ${ }^{\mathrm{d}}$ Health Science and Technology, Aalborg University Hospital, Aalborg, Denmark; ${ }^{\mathrm{e}}$ Department of Cardiology, Herlev and Gentofte University Hospital, Hellerup, Denmark; ${ }^{\mathrm{f}}$ The Danish Heart Foundation, Copenhagen, Denmark; and ${ }^{\mathrm{g}}$ The National Institute of Public Health, University of Southern Denmark, Odense, Denmark.

Received for publication Oct 7, 2017; revisions received Dec 18, 2017; accepted for publication Jan 29, 2018; available ahead of print April 4, 2018.

Address for reprints: Jawad H. Butt, MB, Department of Cardiology, Rigshospitalet, Copenhagen University Hospital, Blegdamsvej 9, 2100 København Ø, Denmark (E-mail: jawad_butt91@hotmail.com).

$0022-5223 / \$ 36.00$

Copyright (c) 2018 by The American Association for Thoracic Surgery

https://doi.org/10.1016/j.jtcvs.2018.01.106
Over the last 4 decades, revascularization by coronary artery bypass grafting (CABG) has been a well-recognized treatment to relieve symptoms of angina pectoris and to improve survival in patients with coronary artery disease (CAD). ${ }^{1}$ Short- and long-term mortality have been

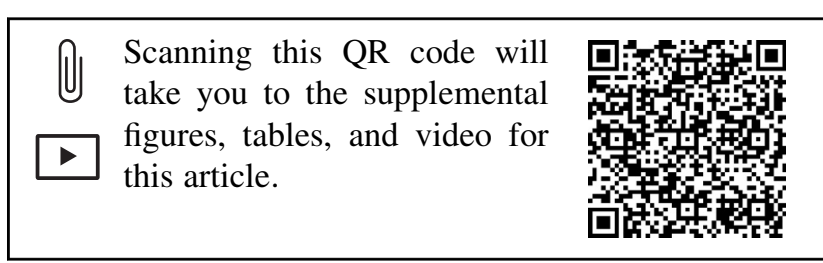



Abbreviations and Acronyms
$\mathrm{CABG}=$ coronary artery bypass grafting
$\mathrm{CAD}=$ coronary artery disease
ICD = International Classification of Diseases
PCI = percutaneous coronary intervention

investigated in patients undergoing $\mathrm{CABG}^{2-15}$; however, studies describing the association between time and causes of death after CABG are sparse and limited by a small number of patients or only investigating a subpopulation. ${ }^{16-21}$ Evaluating long-term cause of death in patients undergoing $\mathrm{CABG}$ is of great importance to enhance current treatment strategies and secondary prevention programs, thereby aiming to reduce mortality in the long-term. From a clinical perspective, knowledge on long-term cause of death will add further to the information provided to the patients at discharge after coronary revascularization about long-term prospects and life expectancy. In patients with ST-segment elevation myocardial infarction undergoing primary percutaneous coronary intervention (PCI), a recent study suggests that cardiovascular death is prevalent in the acute phase, whereas noncardiovascular death gains importance over time. ${ }^{22}$ Whether this may be the case in patients undergoing isolated $\mathrm{CABG}$ has yet to be determined. To address this gap in knowledge, we conducted a nationwide retrospective cohort study to examine short- and long-term mortality and cause of death in patients undergoing isolated $\mathrm{CABG}$.

\section{MATERIAL AND METHODS \\ Data Sources}

The Danish healthcare system, funded by taxes, provides free and equal access to healthcare for all residents regardless of socioeconomic or insurance status. The assignment of a unique and permanent civil registration number to all residents in Denmark allows accurate linkage of nationwide administrative registries at an individual level. For this study, we used 4 different registries. The Danish National Patient Registry holds information on all hospital admissions since 1977 and all surgical procedures since 1996. Each admission is registered by 1 primary diagnosis and, if appropriate, 1 or more secondary diagnosis according to the International Classification of Diseases (ICD-8 until 1993 and ICD-10 from 1994). All surgical procedures, registered according to the NOMESCO Classification of Surgical Procedures used in Nordic countries, are registered by 1 or more codes depending on the type and scale of the operation. ${ }^{23}$ The Danish Registry of Medicinal Product Statistics contains detailed information on all claimed drug prescriptions dispensed from pharmacies in Denmark since 1995. The drugs are classified according to the international Anatomical Therapeutic Chemical system with information on dispensing date, strength, and quantity dispensed. ${ }^{24}$ Information on vital status was obtained from the Danish National Population Registry, in which information on all deaths is registered within 2 weeks after their occurrence. Causes of death classified according to the ICD-10 were obtained from the Danish Registry of Causes of Death. ${ }^{25}$

\section{Study Population, Comorbidity, and Concomitant Pharmacotherapy}

We identified all patients undergoing first-time cardiac surgery between January 1, 1998, and December 31, 2014. To investigate the association between time and cause of death in patients undergoing first-time isolated CABG, we excluded those who underwent $\mathrm{CABG}$ with concomitant valve or other cardiac surgical procedures, were younger than 18 years, and were non-Danish citizens.

Urgency of CABG was classified as elective surgery, urgent surgery (defined as surgery performed during the hospitalization period for acute myocardial infarction), or emergency surgery (defined as surgery within 24 hours after admission for acute myocardial infarction or surgery on the same day as PCI). Patient comorbidity was obtained through the Danish National Patient Registry using hospital discharge diagnoses before admission for CABG (Table E1 shows ICD-8 and ICD-10 codes). Patients with diabetes and hypertension were identified using claimed drug prescriptions as done previously. ${ }^{26}$ Concomitant pharmacotherapy was defined through the Danish Registry of Medicinal Product Statistics as a claimed prescription within 180 days before admission for CABG (Table E2 shows Anatomical Therapeutic Chemical codes).

\section{Causes of Death and Outcomes}

The Danish Registry of Causes of Death holds information about the date, place, and manner of death (natural, accident, violence, suicide, uncertain), as well as the underlying cause (the disease or condition that started the process that led to death) and, if appropriate, 1 or more contributory causes. ${ }^{25}$ On the basis of the underlying cause, we classified causes of death into the following categories: (1) definite cardiovascular; (2) possible cardiovascular; (3) noncardiovascular; and (4) unknown (Table E3 shows ICD-10 codes). On the basis of these categories, we further classified causes of death as cardiovascular or noncardiovascular: The first and second categories were considered a cardiovascular death, and the remaining categories were considered a noncardiovascular death. All-cause mortality, cardiovascular death, and noncardiovascular death were used as end points in separate analyses. Patients were followed from the day of surgery to the occurrence of the event (cardiovascular and noncardiovascular mortality) or the end of the study (December 31, 2014).

\section{Statistical Analyses}

Descriptive data were reported as frequencies and percentages or median with 25 th and 75 th percentiles as appropriate. Baseline characteristics were summarized separately according to 3 time periods in which surgery was performed (ie, 1998-2003, 2004-2009, and 2010-2014), and differences between groups were tested by applying the Cochran-Armitage test for trend for categoric variables and the Kruskal-Wallis test for continuous variables. Cumulative incidence curves were constructed to compare the absolute incidence of cardiovascular and noncardiovascular death while taking into account the competing risk of other causes of death. In addition, landmark analyses of the cumulative incidences of cardiovascular and noncardiovascular mortality were performed and compared using causespecific hazards by the log-rank test; the first analysis covered the firs year after CABG, and additional analyses started at years 1, 3, and 5 and ended 2 years after each time point. The landmarks were selected a priori on the basis of clinically relevant time points. Multivariable cause-specific Cox proportional hazard regression models were used to evaluate changes over time in the risk of all-cause, cardiovascular, and noncardiovascular mortality after 1 and 7 years after CABG, respectively. In addition, factors associated with cardiovascular mortality in the time periods 0 to 1 and 1 to 7 years after $\mathrm{CABG}$ were identified using multivariable cause-specific Cox regression models. All models were adjusted for age, gender, urgency of CABG, prior PCI, all comorbidities listed in Table 1, and the time period in which surgery was performed. The proportional hazards assumption was tested and found valid. Clinical relevant interactions including age, 
TABLE 1. Baseline characteristics of patients undergoing coronary artery bypass grafting

\begin{tabular}{|c|c|c|c|c|c|}
\hline Characteristics & $\begin{array}{l}\text { All patients } \\
N=37,495\end{array}$ & $\begin{array}{c}\text { Period } 1(1998-2003) \\
\quad N=16,649\end{array}$ & $\begin{array}{c}\text { Period } 2(2004-2009) \\
\quad N=12,213\end{array}$ & $\begin{array}{c}\text { Period (2010-2014) } \\
\quad \mathbf{N}=\mathbf{8 6 3 3}\end{array}$ & $P$ value \\
\hline Age, y (median [25th-75th percentile]) & $66(59-72)$ & $66(58-72)$ & $67(60-73)$ & $68(61-74)$ & $<.0001$ \\
\hline Male, N (\%) & $30,037(80.1)$ & $13,150(79.0)$ & $9860(80.7)$ & $7027(81.4)$ & $<.0001$ \\
\hline Surgery, N (\%) & & & & & $<.0001$ \\
\hline Elective & $30,375(81.0)$ & $14,593(87.7)$ & 9715 (79.6) & $6067(70.3)$ & \\
\hline Urgent & 5215 (13.9) & $1599(9.6)$ & $1826(15.0)$ & 1790 (20.7) & \\
\hline Emergency & $1905(5.1)$ & 457 (2.7) & $672(5.5)$ & $776(9.0)$ & \\
\hline Prior PCI, N (\%) & $6462(17.2)$ & $2080(12.5)$ & $2404(19.7)$ & $1978(22.9)$ & $<.0001$ \\
\hline \multicolumn{6}{|l|}{ Comorbidities, N (\%) } \\
\hline Myocardial infarction & $19,064(50.8)$ & $8864(53.2)$ & $6058(49.6)$ & $4142(48.0)$ & $<.0001$ \\
\hline Heart failure & $5398(14.4)$ & $2225(13.4)$ & $1846(15.1)$ & $1327(15.4)$ & $<.0001$ \\
\hline Stroke & $2782(7.4)$ & $1121(6.7)$ & $936(7.7)$ & $725(8.4)$ & $<.0001$ \\
\hline Atrial fibrillation & $2542(6.8)$ & $1096(6.6)$ & $818(6.7)$ & $628(7.3)$ & .05 \\
\hline Hypertension & $21,973(58.6)$ & $9674(58.1)$ & 7395 (60.6) & $4903(56.8)$ & .33 \\
\hline Diabetes & $6326(16.9)$ & $2282(13.7)$ & 2146 (17.6) & $1898(22.0)$ & $<.0001$ \\
\hline Peripheral vascular disease & $2582(6.9)$ & $1135(6.8)$ & $902(7.4)$ & $546(6.3)$ & .34 \\
\hline Malignancy & 2947 (7.9) & $1067(6.4)$ & $1015(8.3)$ & $865(10.0)$ & $<.0001$ \\
\hline Chronic renal failure & $676(1.8)$ & $211(1.3)$ & $249(2.0)$ & $216(2.5)$ & $<.0001$ \\
\hline Chronic obstructive pulmonary disease & $2234(6.0)$ & $929(5.6)$ & $780(6.4)$ & $525(6.1)$ & .04 \\
\hline Liver disease & $500(1.3)$ & $181(1.1)$ & $183(1.5)$ & $136(1.6)$ & $<.0001$ \\
\hline \multicolumn{6}{|l|}{ Concomitant medical treatment, $\mathrm{N}(\%)$} \\
\hline Statins & $23,902(63.8)$ & $8445(50.7)$ & $9204(75.4)$ & $6253(72.4)$ & $<.0001$ \\
\hline Beta-blockers & $23,938(63.8)$ & $11,062(66.4)$ & $8064(66.0)$ & $4812(55.7)$ & $<.0001$ \\
\hline Calcium-blockers & $13,913(37.1)$ & $7133(42.8)$ & $4036(33.1)$ & 2744 (31.8) & $<.0001$ \\
\hline Renin-angiotensin-system inhibitors & $15,996(42.7)$ & $5666(34.0)$ & $5888(48.2)$ & $4442(51.5)$ & $<.0001$ \\
\hline Thiazide & $6179(16.5)$ & $2628(15.8)$ & 2253 (18.5) & $1298(15.0)$ & .87 \\
\hline Loop diuretics & $6276(16.7)$ & $3213(19.3)$ & $1992(16.3)$ & $1071(12.4)$ & $<.0001$ \\
\hline Spironolactone & $1536(4.1)$ & $597(3.6)$ & $577(4.7)$ & $362(4.2)$ & $<.0001$ \\
\hline Clopidogrel & $4444(11.9)$ & $995(6.0)$ & $2364(19.4)$ & $1085(12.6)$ & $<.0001$ \\
\hline Aspirin & $25,499(68.0)$ & $10,833(65.1)$ & $8829(72.3)$ & $5837(67.6)$ & $<.0001$ \\
\hline Oral anticoagulants & $1464(3.9)$ & 597 (3.6) & $452(3.7)$ & $415(4.8)$ & $<.0001$ \\
\hline
\end{tabular}

$P C I$, Percutaneous coronary intervention.

sex, and several comorbidities were tested for and found not significant, unless otherwise stated. There were no missing data for any of the covariates or outcomes. All statistical analyses were performed with SAS statistical software (SAS 9.4, SAS Institute, Inc, Cary, NC).

\section{Sensitivity Analysis}

To test the robustness of our findings, we considered deaths due to unknown causes a cardiovascular death.

\section{Ethics}

Approval for this study was obtained by the Danish Data Protection Agency (No. 2007-58-0015; internal reference: GEH-2014-014, I-Suite no. 02732), and data were anonymized so that individuals could not be identified. Retrospective registry-based studies do not require ethical approval in Denmark.

\section{RESULTS}

A total of 37,495 patients undergoing isolated CABG between January 1, 1998, and December 31, 2014, with no prior cardiac surgery were identified. The median age of the study population was 66 years $(25$ th- 75 th percentile
59-72 years), and $81 \%$ were men. The proportion of patients undergoing emergency and urgent surgery was $5.1 \%$ and $13.9 \%$, respectively. Baseline characteristics stratified according to time periods are summarized in Table 1. Patients who underwent CABG between 2010 and 2014 were older, were more often men, were more likely to undergo urgent or emergency surgery, and had generally more comorbidities compared with those who underwent CABG in the period 1998 to 2003.

\section{Cause of Death}

A total of 12,230 patients died during a median follow-up of 7.4 years. Cause of death was definite cardiovascular in 5172 patients $(42.3 \%$ ), possible cardiovascular in 1287 patients $(10.5 \%)$, noncardiovascular in 5320 patients $(43.5 \%)$, and unknown in 451 patients $(3.7 \%)$. The most common noncardiovascular causes of death were cancer and infection accounting for $2808(23.0 \%)$ and $544(4.5 \%)$ of the total numbers of deaths, respectively (Video 1 ). 


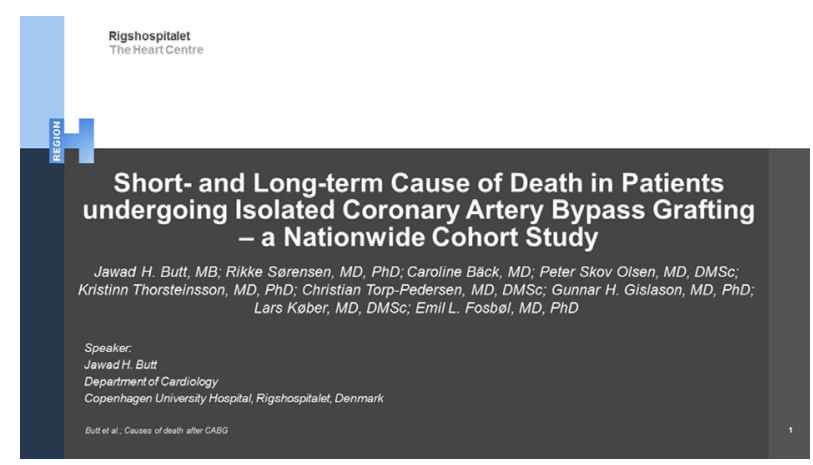

VIDEO 1. Summary of the main findings. Video available at: http://www. jtcvsonline.org/article/S0022-5223(18)30719-0/fulltext.

\section{Cumulative Incidence of Death}

Figure 1 displays the cumulative incidence curves for allcause, cardiovascular, and noncardiovascular mortality. The cumulative incidences of 30-day, 1-year, and 7-year allcause mortality were $2.4 \%, 5.0 \%$, and $21.9 \%$, respectively, and the corresponding cumulative incidences of cardiovascular mortality were $2.1 \%, 3.9 \%$, and $12.0 \%$, respectively.

Results from the landmark analyses of the cumulative incidences of cardiovascular and noncardiovascular mortality at 1,3,5, and 7 years are shown in Central Image/Figure 2. Within the first year after CABG, the incidence of cardiovascular death was higher compared with noncardiovascular death $(3.9 \%$ vs $1.1 \%, P<.001)$. However, the landmark analyses showed similar cumulative incidences of cardiovascular and noncardiovascular deaths in the periods 1 to 3 years postsurgery $(2.3 \%$ vs $2.6 \%, P=.004)$, 3 to 5 years postsurgery $(3.1 \%$ vs $3.2 \%, P=.75)$, and 5 to 7 years postsurgery $(3.7 \%$ vs $4.0 \%, P=.07)$.

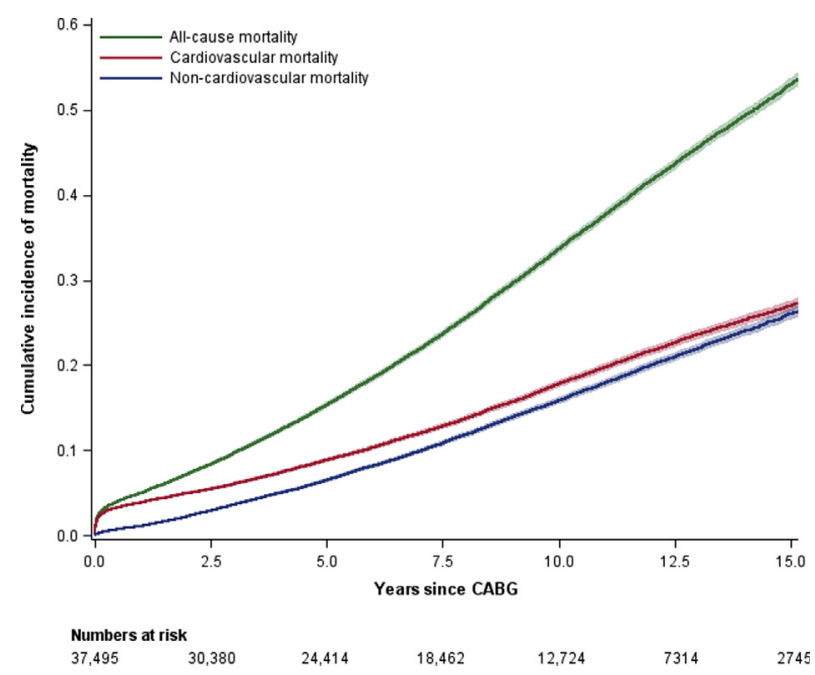

FIGURE 1. Cumulative incidence curves for all-cause mortality, cardiovascular mortality, and noncardiovascular mortality in patients undergoing CABG. $C A B G$, Coronary artery bypass grafting.

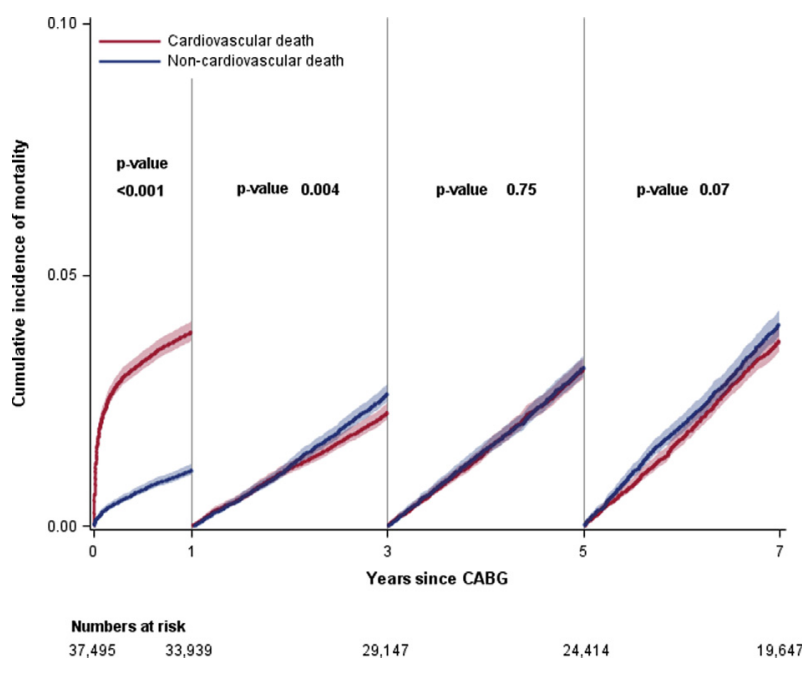

FIGURE 2. Landmark analyses of the cumulative incidences (with confidence intervals) for cardiovascular and noncardiovascular mortality at different time points in patients undergoing CABG. $C A B G$, Coronary artery bypass grafting.

\section{Time Trends}

The crude rates and adjusted risks of all-cause, cardiovascular, and noncardiovascular mortality according to time of surgery are displayed in Figure 3. The crude rate and adjusted risk of 1-year all-cause and cardiovascular mortality decreased during the study period, whereas the risk of noncardiovascular mortality did not differ significantly. Likewise, a decrease in the crude rates and risks of 7-year all-cause and cardiovascular mortality during the study period were observed.

Concomitant medical treatment 1 year postsurgery stratified according to time of surgery is summarized in Table E4. A higher proportion of patients who underwent CABG between 2010 and 2014 were treated with betablockers, statins, aspirin, and renin-angiotensin-system inhibitors compared with those who underwent CABG in the period 1998 to 2003.

\section{Factors Associated With Cardiovascular Mortality}

Results from the multivariate Cox proportional hazard analysis for 1-year cardiovascular mortality are presented in Figure E1, A. Advanced age, female gender, urgency of surgery, and various comorbidities were associated with short-term cardiovascular mortality.

Factors associated with cardiovascular mortality in the period 1 to 7 years after CABG are displayed in Figure E1, $B$. Advanced age, male gender, and various comorbidities were associated with long-term cardiovascular mortality.

\section{Sensitivity Analysis}

To test the robustness of our findings, deaths due to unknown causes were considered cardiovascular. 


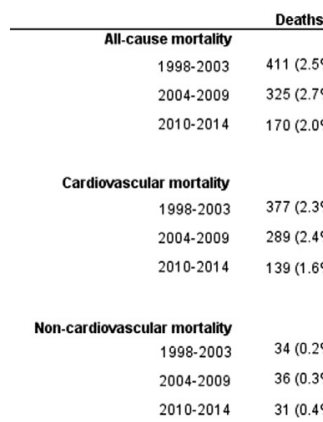

A

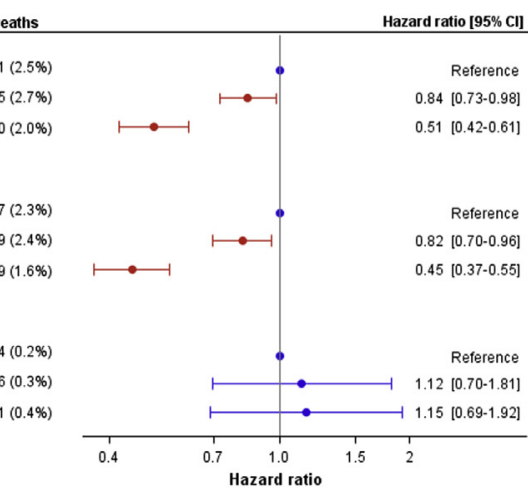

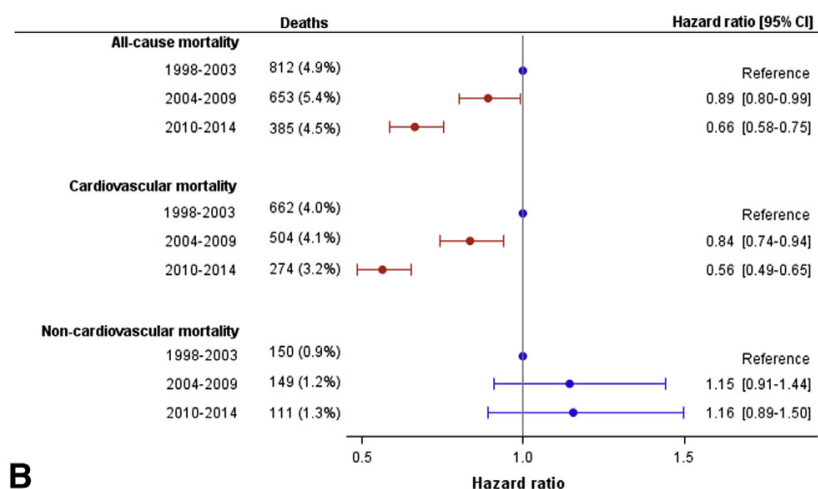

B

Hazard ratio $[95 \% \mathrm{Cl}]$

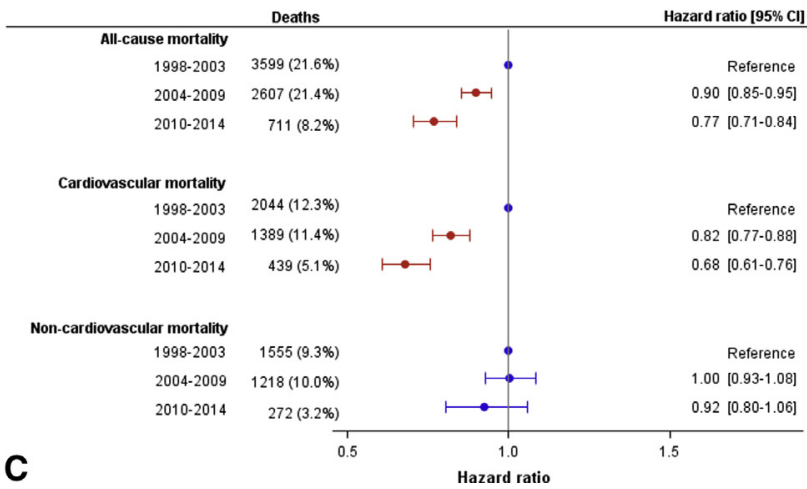

FIGURE 3. Crude rates and adjusted risks of all-cause, cardiovascular, and noncardiovascular mortality according to time of surgery in patients undergoing CABG. A, 30-day mortality. B, 1-year mortality. C, 7-year mortality. CI, confidence interval.

This analysis yielded similar results as the main analysis (Figures E2 and E3).

\section{DISCUSSION}

In this nationwide cohort study, we examined short- and long-term mortality and cause of death in patients undergoing isolated CABG. Our study yielded the following major findings: First, cardiovascular causes were responsible for the majority of deaths within the first year, whereas deaths attributed to noncardiovascular causes gained importance over time elapsed since CABG. Second, the crude rates and adjusted risks of short- and long-term all-cause and cardiovascular mortality decreased during the study period despite an increase in age and burden of comorbidities.

Previous studies have reported on causes of death after CABG; however, these studies were limited by including a small number of patients, investigating subgroups (eg, patients with heart failure, diabetes, complex CAD), or applying specific inclusion and exclusion criteria, thus not reflecting patients in a real-world setting. To our knowledge, this is the first study to examine short- and longterm causes of death in a large all-comers cohort of patients undergoing $\mathrm{CABG}$ on a nationwide scale. In our cohort, $52.5 \%$ of all deaths during a median follow-up of 7.4 years were due to a cardiovascular cause. Another observational study found that $58 \%$ of all deaths $(n=739)$ in a cohort of 2000 patients with more than 10 years follow-up were deemed as having a cardiac cause. ${ }^{16}$ Data from the 5-year follow-up of the randomized Synergy between PCI with Taxus and Cardiac Surgery (SYNTAX) trial showed that only $49.5 \%$ of all deaths in patients treated with CABG were due to a cardiovascular cause. Of note, only patients with complex CAD were enrolled in the SYNTAX trial, and it could be expected that the proportion of cardiovascular deaths was even higher in such a population. However, the low proportion of cardiovascular deaths may partly be explained by the low number of deaths $(\mathrm{n}=97)$ during the follow-up period. In the Surgical Treatment for Ischemic Heart Failure (STICH) trial, 610 patients underwent $\mathrm{CABG}$, and during a median follow-up of 56 months, 218 patients died, in whom $74 \%$ the cause was considered cardiovascular. ${ }^{20}$ The large proportion of cardiovascular deaths and the high mortality observed in the STICH trial are not surprising because the study population comprised only patients with ischemic cardiomyopathy with reduced ejection fraction.

Knowledge of short- and long-term causes of death is crucial to improve treatment strategies and secondary prevention programs. In a recent study, Pedersen and colleagues $^{22}$ examined the association between time and cause of death in patients with ST-segment elevation myocardial infarction undergoing primary PCI. Of note, 
the authors found the incidence of noncardiac causes of death to be higher than cardiac causes in patients surviving the first month after revascularization. ${ }^{22}$ Our findings are in line with these results: We found that cardiovascular deaths were frequent during the first year after $\mathrm{CABG}$, reflecting that the surgical procedure itself is associated with shortterm cardiovascular mortality. Patients who survived the first year appeared increasingly likely to die from other causes than cardiovascular. The risk of competing diseases increases with age, especially in an aging population; in line with this, we found that cancer was the most common cause of noncardiovascular death accounting for $23 \%$ of all deaths after CABG.

Our study revealed that short- and long-term all-cause and cardiovascular mortality rates decreased during the study period despite an increase in age and burden of comorbidities. Several explanations may contribute to these findings. Marked progress in implementing cardiac rehabilitation programs may play a role in the decrease of cardiovascular mortality. In patients with coronary heart disease, exercise-based cardiac rehabilitation provides important health benefits including reductions in cardiovascular mortality and hospitalization. ${ }^{27}$ In Denmark, cardiac rehabilitation is recommended as integrated care with individually planned and coherent rehabilitation across sectors from hospital to municipal; the overall participation rates for patients with coronary heart disease are greater than $70 \%$, although only a part of the patients fulfill a complete comprehensive program. ${ }^{28}$ A greater adoption to guideline-directed use of medications postsurgery (ie, beta-blockers, statins, aspirin, and renin-angiotensin-system inhibitors) may also explain the decrease in long-term cardiovascular mortality during the study period. Another possible explanation may be the increased use of arterial grafts. Although the standard method in Denmark is the use of the left internal thoracic artery to the left anterior descending artery and a saphenous vein graft to the remaining vessels, bilateral thoracic artery grafts and radial arteries are being increasingly used. The superior long-term patency of artery grafts compared with vein grafts is now well established, and mounting evidence supports that the superior patency of artery grafts translates into improved clinical outcomes, including death from cardiovascular causes. $^{29}$

Studies examining factors associated with long-term cardiovascular mortality are sparse because focus mainly has been on all-cause mortality. ${ }^{9,19}$ We found that advanced age, male gender, cardiovascular comorbidities, chronic renal failure, and chronic obstructive pulmonary disease were associated with cardiovascular mortality in the period 1 to 7 years after CABG. The main causes of chronic renal failure in western societies are diabetes and hypertension, both of which are traditional cardiovascular risk factors, and the main cause of chronic obstructive pulmonary disease is smoking, which is also a cardiovascular risk factor. Therefore, chronic renal failure and chronic obstructive pulmonary disease are surrogate markers for high cardiovascular risk.

\section{Study Strengths and Limitations}

The main strength of this study is the completeness of data in a nationwide unselected cohort of 37,495 patients who underwent CABG and were followed for a median 7.4 years in a real-world setting. However, our study has several limitations that need to be acknowledged. The main limitation of this study is inherent to its observational design. Our results are dependent on the classification of causes of death. Determining the exact cause of death is a difficult task and is not always possible. In this study, causes of death were retrieved from the nationwide Danish Registry of Causes of Death. The quality of the data relies mainly on the correctness of the physicians' notification and the coding in the National Board of Health. ${ }^{25}$ Likewise, comorbidities were defined using hospital discharge diagnoses that may vary in quality. The possibility of a differential classification bias related to the classification of causes of death (ie, definite and possible cardiovascular deaths were considered cardiovascular, and noncardiovascular deaths and deaths due to unknown causes were considered noncardiovascular) cannot be excluded. However, when deaths due to unknown causes were considered cardiovascular, we found similar results as the main analysis. We were not able to evaluate the impact of cardiac rehabilitation, use of artery grafts, or on- or off-pump surgery on cardiovascular deaths. In addition, we had no information on important clinical parameters such as left ventricular systolic function, coronary lesions, plasma creatinine levels, body mass index, smoking habits, and lipid levels; thus, the effect of unmeasured confounders cannot be excluded. Moreover, the Danish universal health care system and the high life expectancy and socioeconomic status in Denmark may affect the generalizability of our findings. The prevalence of diabetes in our cohort was a little more than $20 \%$, which is less frequent than other similar studies and also may affect the generalizability of our findings. In this study, we applied landmark analyses to estimate the absolute risk of causes of death at different time points. However, landmark analyses may be limited by the arbitrary selection of the landmark times. To minimize the impact of this potential limitation, we selected the landmarks a priori on the basis of clinically relevant time points. In addition, a recognized disadvantage of the landmark analysis approach is the omission of events occurring earlier to the landmark time, that is, entry in the 1- to 7-year period is conditional on surviving to 1 year. However, we did provide data before the landmark time points. Finally, with a large sample size, very small differences between groups may become statistically significant, although not necessarily clinically meaningful (ie, liver disease in this study). 


\section{CONCLUSIONS}

In patients undergoing first-time isolated $\mathrm{CABG}$, cardiovascular causes were responsible for the majority of deaths within the first year. Deaths due to noncardiovascular causes gained importance over time elapsed since CABG.

\section{Conflict of Interest Statement}

Authors have nothing to disclose with regard to commercial support.

\section{References}

1. Hillis LD, Smith PK, Anderson JL, Bittl JA, Bridges CR, Byrne JG, et al. 2011 ACCF/AHA guideline for coronary artery bypass graft surgery. A report of the American College of Cardiology Foundation/American Heart Association task force on practice guidelines. Developed in collaboration with the American Association for Thoracic Surgery, Society of Cardiovascular Anesthesiologists, and Society of Thoracic Surgeons. J Am Coll Cardiol. 2011;58:e123-210.

2. O'Connor GT, Plume SK, Olmstead EM, Coffin LH, Morton JR, Maloney CT, et al. A regional prospective study of in-hospital mortality associated with coronary artery bypass grafting. The Northern New England cardiovascular disease study group. JAMA. 1991;266:803-9.

3. Boylan MJ, Lytle BW, Loop FD, Taylor PC, Borsh JA, Goormastic M, et al. Surgical treatment of isolated left anterior descending coronary stenosis. Comparison of left internal mammary artery and venous autograft at 18 to 20 years of follow-up. J Thorac Cardiovasc Surg. 1994;107:657-62.

4. Rahimtoola SH, Fessler CL, Grunkemeier GL, Starr A. Survival 15 to 20 years after coronary bypass surgery for angina. J Am Coll Cardiol. 1993;21:151-7.

5. Jones RH, Kesler K, Phillips HR 3rd, Mark DB, Smith PK, Nelson CL, et al. Long-term survival benefits of coronary artery bypass grafting and percutaneous transluminal angioplasty in patients with coronary artery disease. J Thorac Cardiovasc Surg. 1996;111:1013-25.

6. Sergeant PT, Blackstone EH, Meyns BP. Does arterial revascularization decrease the risk of infarction after coronary artery bypass grafting? Ann Thorac Surg. 1998;66:1-11.

7. Yusuf S, Zucker D, Peduzzi P, Fisher LD, Takaro T, Kennedy JW, et al. Effect of coronary artery bypass graft surgery on survival: overview of 10-year results from randomised trials by the coronary artery bypass graft surgery trialists collaboration. Lancet. 1994;344:563-70.

8. Myers WO, Blackstone EH, Davis K, Foster ED, Kaiser GC. CASS registry long term surgical survival. coronary artery surgery study. J Am Coll Cardiol. 1999;33: 488-98.

9. Brooks MM, Jones RH, Bach RG, Chaitman BR, Kern MJ, Orszulak TA, et al. Predictors of mortality and mortality from cardiac causes in the bypass angioplasty revascularization investigation (BARI) randomized trial and registry. For the BARI investigators. Circulation. 2000;101:2682-9.

10. Shahian DM, O’Brien SM, Sheng S, Grover FL, Mayer JE, Jacobs JP, et al. Predictors of long-term survival after coronary artery bypass grafting surgery: results from the Society of Thoracic Surgeons Adult Cardiac Surgery Database (the ASCERT study). Circulation. 2012;125:1491-500.

11. Wu C, Camacho FT, Wechsler AS, Lahey S, Culliford AT, Jordan D, et al. Risk score for predicting long-term mortality after coronary artery bypass graft surgery. Circulation. 2012;125:2423-30.

12. Sipahi I, Akay MH, Dagdelen S, Blitz A, Alhan C. Coronary artery bypass grafting vs percutaneous coronary intervention and long-term mortality and morbidity in multivessel disease: meta-analysis of randomized clinical trials of the arterial grafting and stenting era. JAMA Intern Med. 2014;174:223-30.

13. Hlatky MA, Boothroyd DB, Bravata DM, Boersma E, Booth J, Brooks MM, et al Coronary artery bypass surgery compared with percutaneous coronary interven- tions for multivessel disease: a collaborative analysis of individual patient data from ten randomised trials. Lancet. 2009;373:1190-7.

14. Bradshaw PJ, Jamrozik K, Le M, Gilfillan I, Thompson PL. Mortality and recurrent cardiac events after coronary artery bypass graft: long term outcomes in a population study. Heart. 2002;88:488-94.

15. Thorsteinsson K, Fonager K, Merie C, Gislason G, Kober L, Torp-Pedersen C, et al. Age-dependent trends in postoperative mortality and preoperative comorbidity in isolated coronary artery bypass surgery: a nationwide study. Eur J Cardiothorac Surg. 2016;49:391-7.

16. Herlitz J, Brandrup-Wognsen G, Caidahl K, Haglid-Evander M, Hartford M, Karlson B, et al. Cause of death during 13 years after coronary artery bypass grafting with emphasis on cardiac death. Scand Cardiovasc J. 2004;38: 283-6.

17. Herlitz J, Karlson BW, Sjoland H, Brandrup-Wognsen G, Haglid M, Karlsson T, et al. Long term prognosis after $\mathrm{CABG}$ in relation to preoperative left ventricular ejection fraction. Int J Cardiol. 2000;72:163-71; discussion 73-4.

18. O'Connor GT, Birkmeyer JD, Dacey LJ, Quinton HB, Marrin CA, Birkmeyer NJ, et al. Results of a regional study of modes of death associated with coronary artery bypass grafting. Northern New England cardiovascular disease study group. Ann Thorac Surg. 1998;66:1323-8.

19. Milojevic M, Head SJ, Parasca CA, Serruys PW, Mohr FW, Morice MC, et al. Causes of death following PCI versus CABG in complex CAD: 5-year followup of SYNTAX. J Am Coll Cardiol. 2016;67:42-55.

20. Carson P, Wertheimer J, Miller A, O'Connor CM, Pina IL, Selzman C, et al. The STICH trial (surgical treatment for ischemic heart failure): mode-of-death results, JACC Heart Fail. 2013:1:400-8.

21. Holmes DR Jr, Kim LJ, Brooks MM, Kip KE, Schaff HV, Detre KM, et al. The effect of coronary artery bypass grafting on specific causes of long-term mortality in the bypass angioplasty revascularization investigation. $J$ Thorac Cardiovasc Surg. 2007:134:38-46.e1.

22. Pedersen F, Butrymovich V, Kelbaek H, Wachtell K, Helqvist S, Kastrup J, et al. Short- and long-term cause of death in patients treated with primary PCI for STEMI. J Am Coll Cardiol. 2014;64:2101-8.

23. Lynge E, Sandegaard JL, Rebolj M. The Danish national patient register. Scand J Public Health. 2011;39(7 Suppl):30-3.

24. Kildemoes HW, Sorensen HT, Hallas J. The Danish national prescription registry. Scand J Public Health. 2011;39(7 Suppl):38-41.

25. Helweg-Larsen K. The Danish register of causes of death. Scand J Public Health. 2011;39(7 Suppl):26-9.

26. Olesen JB, Lip GY, Hansen ML, Hansen PR, Tolstrup JS, Lindhardsen J, et al Validation of risk stratification schemes for predicting stroke and thromboembolism in patients with atrial fibrillation: nationwide cohort study. BMJ. 2011;342: d 124.

27. Anderson L, Thompson DR, Oldridge N, Zwisler AD, Rees K, Martin N, et al Exercise-based cardiac rehabilitation for coronary heart disease. Cochrane Database Syst Rev. 2016;Cd001800

28. Danish Healthcare Services. Dansk Hjerterehabiliteringsdatabase. Strukturelle forhold og opgørelse af patientgrundlag og aktivitet i Landspatientregisteret, 2013, Styregruppen for Dansk Hjerterehabiliteringsdatabase [The Danish cardiac rehabilitation database. Structural conditions and inventory of patient population and activity in the national patient registry, 2013, The Steering Committee for The Danish cardiac rehabilitation database]. Available at: https://www. sundhed.dk/content/cms/93/59693_hjerterehab2014.pdf. Accessed December $18,2017$.

29. Taggart DP. Current status of arterial grafts for coronary artery bypass grafting Ann Cardiothorac Surg. 2013:2:427-30.

Key Words: coronary artery bypass grafting, coronary artery disease, epidemiology, mortality 
Within 1 year after CABG

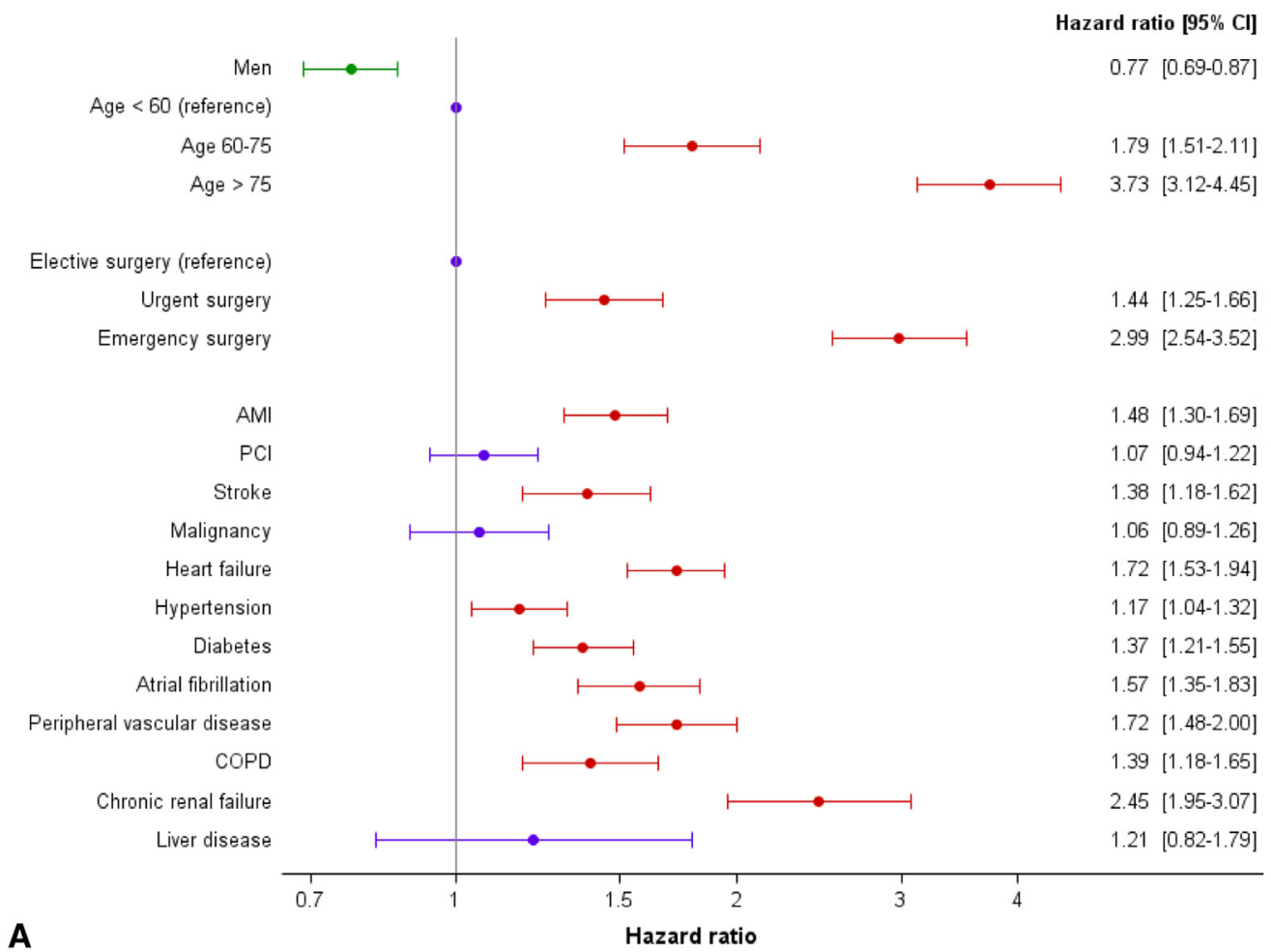

In the period, 1-7 years after CABG

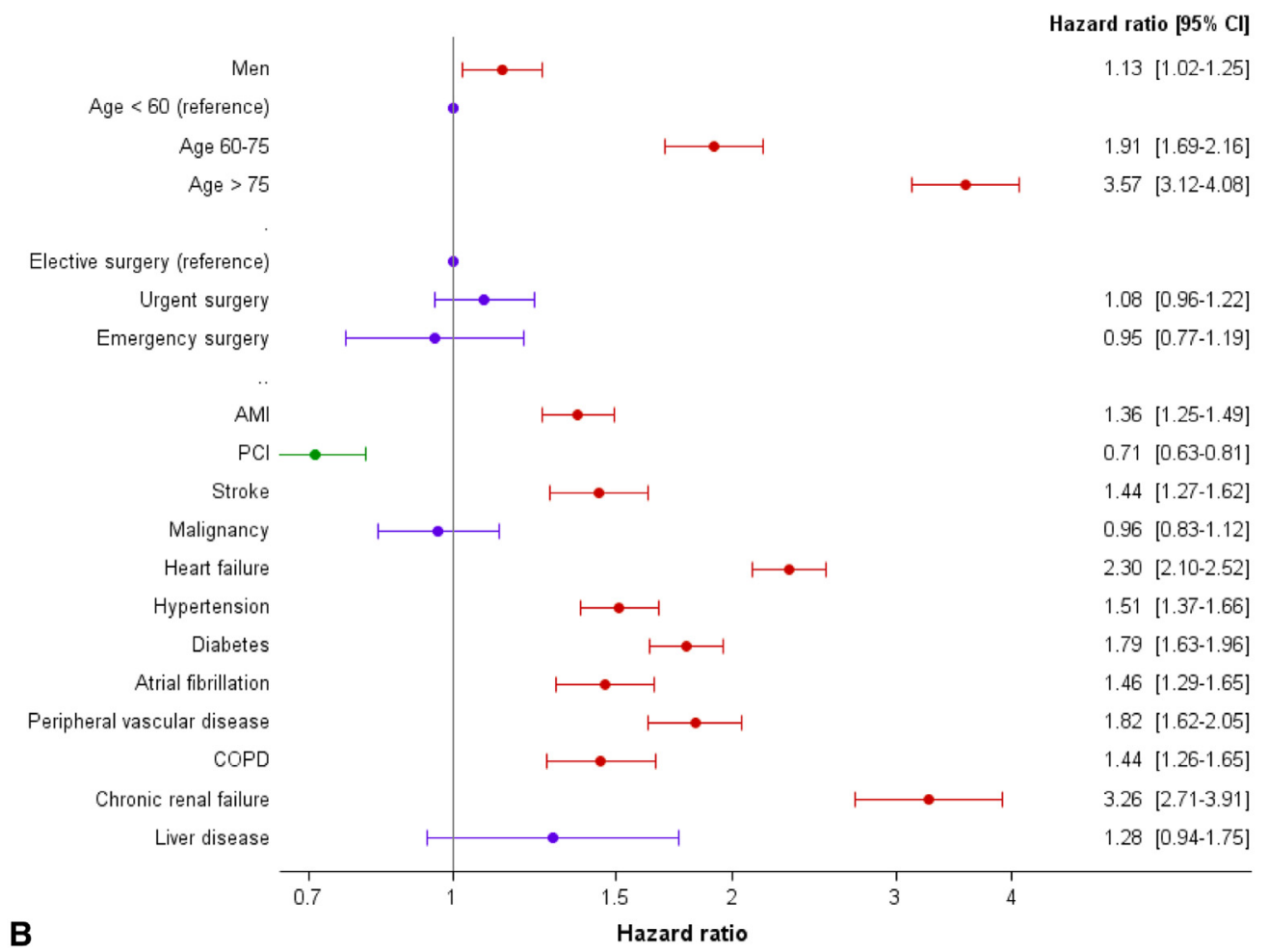

FIGURE E1. Results from the Cox proportional hazard analyses examining factors associated with cardiovascular mortality in patients undergoing CABG. A, Within 1 year after CABG. B, In the period 1 to 7 years after CABG. CI, Confidence interval; AMI, acute myocardial infarction; PCI, percutaneous coronary intervention; $C O P D$, chronic obstructive pulmonary disease. 


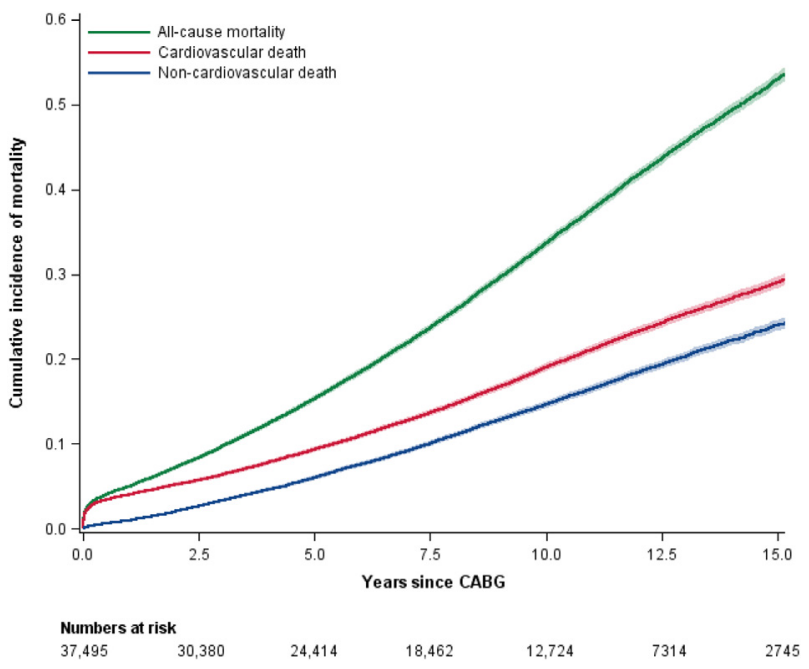

FIGURE E2. Cumulative incidence curves for all-cause mortality, cardiovascular mortality (definite cardiovascular, possible cardiovascular, and unknown), and noncardiovascular mortality in patients undergoing CABG. $C A B G$, Coronary artery bypass grafting.

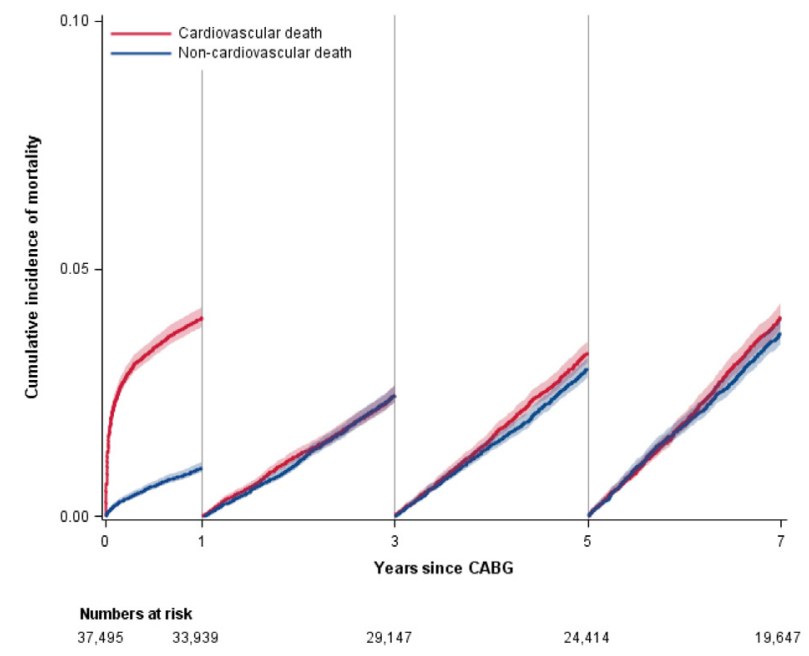

FIGURE E3. Landmark analyses of the cumulative incidences (with confidence intervals) for cardiovascular (definite cardiovascular, possible cardiovascular, and unknown) and noncardiovascular mortality at different time points in patients undergoing CABG. $C A B G$, Coronary artery bypass grafting.
TABLE E1. International Classification of Diseases 8 and 10 codes for comorbidities

\begin{tabular}{|c|c|}
\hline Comorbidity & ICD-8 and ICD-10 codes \\
\hline Acute myocardial infarction & $\begin{array}{l}\text { ICD-10: I21, I22 } \\
\text { ICD-8: } 410\end{array}$ \\
\hline Heart failure & $\begin{array}{l}\text { ICD-10: I42, I50, J81, I110, } \\
\text { I130, I132 } \\
\text { ICD-8: } 425,428,4270,4271\end{array}$ \\
\hline Stroke & $\begin{array}{l}\text { ICD-10: I60, I61, I63, I64 } \\
\text { ICD-8: 430-434, } 436\end{array}$ \\
\hline Atrial fibrillation & $\begin{array}{l}\text { ICD-10: I48 } \\
\text { ICD-8: } 4274\end{array}$ \\
\hline Peripheral vascular disease & $\begin{array}{l}\text { ICD-10: I70, I74 } \\
\text { ICD-8: } 443\end{array}$ \\
\hline Malignancy & $\begin{array}{l}\text { ICD-10: C00-C97 } \\
\text { ICD-8: } 140-209\end{array}$ \\
\hline Chronic renal failure & $\begin{array}{l}\text { ICD-10: N18, I12, I13, T858, } \\
\text { T859, Z992 } \\
\text { ICD-8: } 585\end{array}$ \\
\hline $\begin{array}{l}\text { Chronic obstructive } \\
\text { pulmonary disease }\end{array}$ & $\begin{array}{l}\text { ICD-10: J42, J44 } \\
\text { ICD-8: 490-492 }\end{array}$ \\
\hline Liver disease & $\begin{array}{l}\text { ICD-10: K70-K77, K704, } \\
\text { K766, K711, B150, B160, } \\
\text { B190 } \\
\text { ICD-8: } 571,572,456\end{array}$ \\
\hline
\end{tabular}

$I C D$, International Classification of Diseases.

TABLE E2. Anatomic Therapeutic Chemical classification codes for pharmacotherapy

\begin{tabular}{ll}
\hline \multicolumn{1}{c}{ Pharmacotherapy } & \multicolumn{1}{c}{ ATC codes } \\
\hline Beta-blockers & C07, C09BX \\
$\begin{array}{l}\text { Calcium channel blockers } \\
\begin{array}{l}\text { Renin-angiotensin-system } \\
\text { inhibitors }\end{array}\end{array}$ & C08, C07F, C09BB, C09DB \\
Thiazides & C03A, C07B, C07D, \\
& C09XA52, C03EA01 \\
\hline Loop diuretics & C03C, C03EB01, C03EB02 \\
Spironolactone & C03DA01 \\
\hline Statins & C10AA \\
Anti-diabetics & A10 \\
\hline Acetylsalicylic acid & B01AC06 \\
Clopidogrel & B01AC04 \\
\hline Oral anticoagulants & B01AA, B01AE, B01AF \\
\hline
\end{tabular}

ATC, Anatomical Therapeutic Chemical. 
TABLE E3. International Classification of Diseases 10 codes for causes of death

\section{Cause of death}

ICD-10 codes

Definitive cardiovascular

Acute rheumatic pericarditis

Acute rheumatic endocarditis

Acute rheumatic myocarditis

I01.1

Rheumatic myocarditis

Rheumatic diseases of endocardium, valve unspecified

$\mathrm{I} 01.2$

Chronic rheumatic pericarditis

I09.0

I09.1

I09.2

Chertensive heart disease with (congestive) heart failure

I11.0

Hypertensive heart and renal disease with (congestive) heart failure

I13.0

Hypertensive heart and renal disease with both (congestive) heart failure and renal failure

I13.2

Acute myocardial infarction

I 21

Subsequent myocardial infarction

$\mathrm{I} 22$

Certain current complications following acute myocardial infarction $\quad$ I23

Other acute ischemic heart diseases

$\mathrm{I} 24$

Pulmonary embolism

I26

Acute pericarditis

I30

Other diseases of pericardium

I31

Pericarditis in diseases classified elsewhere $\quad$ I32

Acute and subacute endocarditis

I33

Endocarditis, valve unspecified

Endocarditis, valve unspecified, in diseases classified elsewhere

I38

Acute myocarditis

I39.8

Myocarditis in diseases classified elsewhere

I40

Cardiomyopathy

I41

Cardiomyopathy in diseases classified elsewhere

I42

Heart failure

I43

I50

$\begin{array}{ll}\text { Subarachnoid hemorrhage } & \text { I60 }\end{array}$

$\begin{array}{ll}\text { Intracerebral hemorrhage } & \text { I61 }\end{array}$

Other nontraumatic intracranial hemorrhage $\quad$ I62

Cerebral infarction $\quad$ I63

$\begin{array}{ll}\text { Stroke, not specified as hemorrhage or infarction } & \text { I64 }\end{array}$

$\begin{array}{ll}\text { Dissection of aorta [any part] } & \text { I71.0 }\end{array}$

$\begin{array}{ll}\text { Thoracic aortic aneurysm, ruptured } & \text { I71.1 }\end{array}$

$\begin{array}{ll}\text { Abdominal aortic aneurysm, ruptured } & \text { I71.3 }\end{array}$

$\begin{array}{ll}\text { Thoracoabdominal aortic aneurysm, ruptured } & \text { I71.5 }\end{array}$

$\begin{array}{ll}\text { Aortic aneurysm of unspecified site, ruptured } & \text { I71.8 }\end{array}$

$\begin{array}{ll}\text { Embolism and thrombosis of abdominal aorta } & \text { I74.0 }\end{array}$

$\begin{array}{ll}\text { Embolism and thrombosis of other and unspecified parts of aorta } & \text { I74.1 }\end{array}$

Possible cardiovascular

Other I-diagnoses

All I-diagnoses except those mentioned above

Diabetes

E10-E14

Chronic renal failure and diabetes as comorbidity

N18 AND diabetes as comorbidity

Unknown

R95-R99, no information on underlying

cause

\begin{tabular}{lc} 
Noncardiovascular & C00-C97 \\
Cancer & A00-B99, J12-J16, J18, J84, J851, J852, J86, \\
Infection & N10-N12, N30, N390, G01-G04, G038, \\
& G039, K57, R091 \\
Respiratory disease & J00-J99 (except J12-J16, J18, J84, J851, J852, \\
& J86) \\
Renal disease & N00-N99 (except N10-N12, N30) \\
Other & All ICD-codes not mentioned above \\
\hline
\end{tabular}

ICD, International Classification of Diseases. 
TABLE E4. Concomitant medical treatment $1 \mathrm{y}$ postsurgery in patients undergoing coronary artery bypass grafting according to time of surgery

\begin{tabular}{|c|c|c|c|c|c|}
\hline $\begin{array}{c}\text { Concomitant medical } \\
\text { treatment, } \mathbf{N}(\%)\end{array}$ & $\begin{array}{l}\text { All patients } \\
\mathrm{N}=\mathbf{3 3 , 9 3 9}\end{array}$ & $\begin{array}{c}\text { Period } 1(\mathbf{1 9 9 8 - 2 0 0 3 )} \\
\quad \mathrm{N}=\mathbf{1 5 , 8 3 7}\end{array}$ & $\begin{array}{c}\text { Period } 2(2004-2009) \\
\quad N=11,560\end{array}$ & $\begin{array}{c}\text { Period (2010-2014) } \\
\quad \mathrm{N}=6542\end{array}$ & $P$ value \\
\hline Statins & $27,802(81.9)$ & $11,238(71.0)$ & $10,674(92.3)$ & $5890(90.0)$ & $<.0001$ \\
\hline Beta-blockers & $23,322(68.7)$ & $9516(60.1)$ & $8861(76.7)$ & 4945 (75.6) & $<.0001$ \\
\hline Calcium-blockers & $7876(23.2)$ & $3102(19.6)$ & 2955 (25.6) & $1819(27.8)$ & $<.0001$ \\
\hline $\begin{array}{l}\text { Renin-angiotensin-system } \\
\text { inhibitors }\end{array}$ & $17,023(50.2)$ & $6372(40.2)$ & $6702(58.0)$ & $3949(60.4)$ & $<.0001$ \\
\hline Thiazide & $5161(15.2)$ & $2395(15.1)$ & 1955 (16.9) & $811(12.4)$ & $<.0001$ \\
\hline Loop diuretics & $8534(25.2)$ & $3928(24.8)$ & 3057 (26.4) & 1549 (23.7) & .50 \\
\hline Spironolactone & $2604(7.7)$ & $1005(6.4)$ & $985(8.5)$ & $614(9.4)$ & $<.0001$ \\
\hline Clopidogrel & $5163(15.2)$ & $693(4.4)$ & $2903(25.1)$ & $1567(24.0)$ & $<.0001$ \\
\hline Aspirin & 27,471 (80.9) & $11,756(74.2)$ & $10,126(87.6)$ & $5589(85.4)$ & $<.0001$ \\
\hline Oral anticoagulants & $2148(6.3)$ & $772(4.9)$ & $748(6.5)$ & $628(9.6)$ & $<.0001$ \\
\hline
\end{tabular}

